\title{
LOW MICROCIRCULATORY PERFUSED VESSEL DENSITY AND HIGH HETEROGENEITY ARE ASSOCIATED WITH INCREASED INTENSITY AND DURATION OF LACTIC ACIDOSIS AFTER CARDIAC SURGERY WITH CARDIOPULMONARY BYPASS
}

\author{
John C. Greenwood, ${ }^{\star}$ David H. Jang, ${ }^{\dagger}$ Audrey E. Spelde, ${ }^{\ddagger}$ Jacob T. Gutsche, ${ }^{\ddagger}$ \\ Jiri Horak, ${ }^{\ddagger}$ Michael A. Acker, ${ }^{\S}$ Todd J. Kilbaugh," Frances S. Shofer, \\ John G.T. Augoustides, ${ }^{\ddagger}$ Jan Bakker, ${ }^{* \star+t \neq \neq}$ and Benjamin S. Abella ${ }^{\$ \$ \$}$ \\ "Division of Critical Care Medicine, Department of Emergency Medicine, Department of Anesthesiology \\ and Critical Care, Center for Resuscitation Science, Perelman School of Medicine at the University of \\ Pennsylvania, Philadelphia, Pennsylvania; ${ }^{\dagger}$ Division of Medical Toxicology and Critical Care Medicine, \\ Department of Emergency Medicine, Center for Resuscitation Science, Perelman School of Medicine at \\ the University of Pennsylvania, Philadelphia, Pennsylvania; ${ }^{\ddagger}$ Department of Anesthesiology and Critical \\ Care, Perelman School of Medicine at the University of Pennsylvania, Philadelphia, Pennsylvania; \\ ${ }^{\S}$ Division of Cardiovascular Surgery, Department of Surgery, Perelman School of Medicine at the \\ University of Pennsylvania, Philadelphia, Pennsylvania; "Department of Anesthesiology and Critical Care \\ Medicine, Center for Mitochondrial and Epigenomic Medicine, The Children's Hospital of Philadelphia, \\ Philadelphia, Pennsylvania; "Department of Epidemiology and Biostatistics, Department of Emergency \\ Medicine Hospital of the University of Pennsylvania, Philadelphia, Pennsylvania; * Division of Pulmonary, \\ Allergy, and Critical Care Medicine, Columbia University Medical Center, New York, New York; \\ ${ }^{+\dagger}$ Department of Intensive Care Adults, Erasmus MC University Medical Center, Rotterdam, the \\ Netherlands; ${ }^{\ddagger \ddagger}$ Department of Intensive Medicine, The Pontifical Catholic University of Chile, Santiago, \\ Región Metropolitana, Chile; and ${ }^{\S}$ Department of Emergency Medicine, Center for Resuscitation \\ Science, Perelman School of Medicine at the University of Pennsylvania, Philadelphia, Pennsylvania
}

Received 28 Oct 2020; first review completed 13 Nov 2020; accepted in final form 14 Dec 2020

\begin{abstract}
Introduction: Lactic acidosis after cardiac surgery with cardiopulmonary bypass is common and associated with an increase in postoperative morbidity and mortality. A number of potential causes for an elevated lactate after cardiopulmonary bypass include cellular hypoxia, impaired tissue perfusion, ischemic-reperfusion injury, aerobic glycolysis, catecholamine infusions, and systemic inflammatory response after exposure to the artificial cardiopulmonary bypass circuit. Our goal was to examine the relationship between early abnormalities in microcirculatory convective blood flow and diffusive capacity and lactate kinetics during early resuscitation in the intensive care unit. We hypothesized that patients with impaired microcirculation after cardiac surgery would have a more severe postoperative hyperlactatemia, represented by the lactate time-integral of an arterial blood lactate concentration greater than $2.0 \mathrm{mmol} / \mathrm{L}$. Methods: We measured sublingual microcirculation using incident darkfield video microscopy in 50 subjects on intensive care unit admission after cardiac surgery. Serial measurements of systemic hemodynamics, blood gas, lactate, and catecholamine infusions were recorded each hour for the first $6 \mathrm{~h}$ after surgery. Lactate area under the curve (AUC) was calculated over the first $6 \mathrm{~h}$. The lactate AUC was compared between subjects with normal and low perfused vessel density (PVD $<18 \mathrm{~mm} / \mathrm{mm}^{2}$ ), high microcirculatory heterogeneity index (MHI >0.4), and low vessel-by-vessel microvascular flow index (MFIv <2.6). Results: Thirteen $(26 \%)$ patients had a low postoperative PVD, 20 patients (40\%) had a high MHI, and $26(52 \%)$ patients had a low MFIv. Patients with low perfused vessel density had higher lactate AUC compared with subjects with a normal PVD (22.3 [9.4-31.0] vs. 2.6 [08.8]; $P<0.0001)$. Patients with high microcirculatory heterogeneity had a higher lactate AUC compared with those with a normal MHI (2.5 [0.1-8.2] vs. 13.1 [3.7-31.1]; $P<0.001)$. We did not find a difference in lactate AUC when comparing high
\end{abstract}

Address reprint requests to John C. Greenwood, MD, Department of Emergency Medicine, Hospital of the University of Pennsylvania. 3400 Spruce Street, Philadelphia, PA 19104. E-mail: john.greenwood@pennmedicine.upenn.edu

This study was approved by our institutional review board (IRB \# 829765) and informed consent was obtained prior to enrollment. All consent forms were copied in triplicate, one given to the subject, the second placed in the official medical record, the third kept in a secured location within the PI's office.

JCG consent to the publication of this work if accepted by the journal.

All original data and materials are kept in a locally managed REDCap database at the University of Pennsylvania. Deidentified microcirculation data are available online, uploaded to open access Zenodo database found here: https://doi.org/10.5281/ zenodo.4106205.

JCG made substantial contributions to the conception or design of the work; the acquisition, analysis, or interpretation of data; drafted the work or substantively revised the manuscript. DHJ made substantial contributions to the conception or design of the work; the analysis and interpretation of data; substantively revised the manuscript. AES made substantial contributions to the acquisition, analysis, or interpretation of data; drafted the work or substantively revised the manuscript. JTG made substantial contributions to the conception or design of the work; drafted the work or substantively revised the manuscript. JH made substantial contributions to the conception or design of the work; drafted the work or substantively revised the manuscript. MAA made substantial contributions to the conception or design of the work; drafted the work or substantively revised the manuscript. TJK made substantial contributions to the conception or design of the work; the analysis, or interpretation of data; drafted the work or substantively revised the manuscript. FSS made substantial contributions to the conception or design of the work; the analysis, or interpretation of data; drafted the work or substantively revised the manuscript. JGTA made substantial contributions to the conception or design of the work; the analysis, or interpretation of data; drafted the work or substantively revised the manuscript. JB made substantial contributions to the conception or design of the work; the analysis, or interpretation of data; drafted the work or substantively revised the manuscript. BSA made substantial contributions to the conception or design of the work; the analysis, or interpretation of data; drafted the work or substantively revised the manuscript.

The authors report no conflicts of interest.

Supplemental digital content is available for this article. Direct URL citation appears in the printed text and is provided in the HTML and PDF versions of this article on the journal's Web site (www.shockjournal.com).

DOI: 10.1097/SHK.0000000000001713

Copyright (C) 2021 by the Shock Society 
and low MFIv. Conclusion: Low perfused vessel density and high microcirculatory heterogeneity are associated with an increased intensity and duration of lactic acidosis after cardiac surgery with cardiopulmonary bypass.

KEYWORDS—Cardiac surgery, circulatory shock, lactate, microcirculation, resuscitation

\begin{abstract}
ABBREVIATIONS—CABG—coronary artery bypass grafting; CBP—cardiopulmonary bypass; Cl—cardiac Index; CVP— central venous pressure; ICU_intensive care unit; IDF_incident dark field; IQR —interquartile range; MAP_mean arterial pressure; MFI—microvascular flow index; MFIv—microvascular flow index vessel by vessel; MHI—microcirculatory heterogeneity index; PPV_-proportion of perfused vessels; PVD_perfused vessel density; REDCap_research electronic data capture; SD—standard deviation; $\mathrm{SvO}_{2}$ - mixed venous oxygen saturation; SVRi-systemic vascular resistance index; TVD—-total vessel density
\end{abstract}

\section{INTRODUCTION}

Circulatory shock after cardiac surgery is estimated to occur in $25 \%$ to $40 \%$ of patients, caused by hemorrhage, ischemicreperfusion injury, systemic inflammatory response, and microemboli formation which can all impair microcirculatory blood flow (1-3).

Hyperlactatemia is used as a marker of inadequate tissue perfusion and is regularly followed after cardiac surgery. There are a number of potential causes for an elevated lactate after cardiopulmonary bypass including cellular hypoxia, impaired tissue perfusion, ischemic-reperfusion injury, aerobic glycolysis, catecholamine infusions, and systemic inflammatory response after exposure to the artificial cardiopulmonary bypass circuit (4-6). Although clinical outcomes are often good after cardiac surgery, both moderate $(2 \mathrm{mmol} / \mathrm{L}-4 \mathrm{mmol} /$ $\mathrm{L})$, severe $(\geq 4 \mathrm{mmol} / \mathrm{L})$, and prolonged abnormalities in postoperative lactate are associated with increased morbidity and mortality (7-9). Early identification of perfusion abnormalities with handheld video microscopy is appealing, since a rise in lactate level requires a period of ischemia to have already taken place. Unlike blood lactate and more widely used methods to evaluate the microcirculation (e.g., mottling score, capillary refill time, etc.), evaluation with handheld video microscopy has allowed for a more detailed assessment of perfusion derangements such as global versus heterogeneous reductions in red blood cell velocity, capillary microthrombosis, and reductions in functional capillary density which may provide insight to the mechanism of circulatory shock.

Abnormal microcirculatory blood flow is an important and potentially reversible cause of tissue hypoxia causing lactic acidosis. Isolated experiments have reported inconsistent findings regarding impaired postoperative microcirculation and its relationship to traditional measures of oxygen delivery and utilization (10-14). Decreases in microcirculatory diffusive capacity and convective blood flow after cardiac surgery have been described $(3,12)$. We recently found severe reductions in postoperative perfused vessel density (PVD) were associated with an increase in measured lactate concentration and postoperative organ injury (15). Unfortunately, the relationship between postoperative microcirculation abnormalities and lactate kinetics remains unclear $(3,16)$.

Our study aimed to examine the relationship between early abnormalities in postoperative microcirculation and lactate kinetics during the early resuscitation in the intensive care unit. We hypothesized that the severity of postoperative hyperlactatemia, represented by the lactate time-integral of an arterial blood lactate concentration greater than $2.0 \mathrm{mmol} / \mathrm{L}$ (area under the curve [AUC]), would be greater in patients with impaired microcirculation.

\section{MATERIALS AND METHODS}

\section{Study design}

We performed an exploratory prospective study at a single, tertiary academic cardiovascular surgical intensive care unit (ICU). The study protocol was approved by our institutional review board (IRB \#829765). Patients were screened for eligibility on days the investigators were available to perform microcirculation imaging over a 12-month period from May 2019 through January 2020. Adult patients (age $>18$ years) receiving elective coronary artery bypass grafting or valvular surgery requiring cardiopulmonary bypass were approached for enrollment in the pre-operative staging area or medical ward prior to their transfer to the operating room. Patients were excluded from the study if they received hypothermic circulatory arrest, were unable to tolerate microcirculatory flow image acquisition (e.g., nonintubated patients dependent upon oxygen by facemask or nonrebreather), could not cooperate with the examination (e.g., poor mouth opening, agitation), unable to provide written consent, had recent maxillofacial surgery, or oral mucosal bleeding. Written informed consent was obtained from the patient prior to enrollment. Study data was collected and recorded using the Research Electronic Data Capture electronic data capture tools hosted at the University of Pennsylvania $(17,18)$.

\section{Intraoperative care}

All patients were monitored with an invasive arterial blood pressure line, five-lead electrocardiography, pulse oximetry, end-tidal capnography and gas analyzer, a pulmonary artery catheter with core temperature probe, central venous pressure monitoring, and transesophageal echocardiography. Induction of anesthesia was performed with intravenous fentanyl (up to $5 \mu \mathrm{g} / \mathrm{kg}$ ), propofol ( $1 \mathrm{mg} / \mathrm{kg}-2 \mathrm{mg} / \mathrm{kg})$, and vecuronium $(0.1 \mathrm{mg} / \mathrm{kg})$ prior to endotracheal intubation. Anesthesia was maintained with isoflurane in a mixture of oxygen and air. Additional doses of muscle relaxant and fentanyl were given as needed. All patients were mechanically ventilated with lung protective ventilation during the operative case. Tidal volumes were prescribed to $6 \mathrm{~mL} / \mathrm{kg}$ to $8 \mathrm{~mL} / \mathrm{kg}$ of ideal body weight and a positive end-expiratory pressure of $5 \mathrm{~cm}$ to $10 \mathrm{~cm} \mathrm{H}_{2} \mathrm{O}$ with the respiratory rate adjusted to achieve an end-tidal carbon dioxide measurement of $30 \mathrm{~mm} \mathrm{Hg}$ to $35 \mathrm{~mm} \mathrm{Hg}$. Prior to CPB, anticoagulation with $300 \mathrm{IU} / \mathrm{kg}$ of heparin was administered to achieve an activated clotting time $>450 \mathrm{~s}$. A bypass flow rate of $2.2 \mathrm{~L} / \mathrm{min} / \mathrm{m}^{2}$ to $2.4 \mathrm{~L} / \mathrm{min} / \mathrm{m}^{2}$ was delivered with a mean arterial pressure (MAP) maintained $>60 \mathrm{~mm} \mathrm{Hg}$. Patients were maintained at $30^{\circ} \mathrm{C}$ to $32^{\circ} \mathrm{C}$ during the procedure. Microplegia or del Nido cardioplegia solution was used based on surgeon preference. Intravenous phenylephrine was administered as needed for hypotension. After weaning from bypass, a MAP $>60 \mathrm{~mm} \mathrm{Hg}$, cardiac index $>2.2 \mathrm{~L} / \mathrm{min} / \mathrm{m}^{2}$ was achieved with the administration of fluid boluses and vasoactive titration (phenylephrine or epinephrine infusion). Cardiac function and filling status were reviewed and optimized at the end of the operative case with the assistance of transesophageal echocardiography. Heparin-based anticoagulation was reversed with $1 \mathrm{mg}$ of protamine for each $100 \mathrm{IU}$ of heparin given to restore activated clotting time to baseline values.

\section{Hemodynamic and physiologic measurements}

Postoperative microcirculation measurements were obtained within the first hour of arrival to the ICU. Systemic hemodynamic data along with perfusion data were collected upon ICU admission, then hourly during the first $6 \mathrm{~h}$ of postoperative care. Cardiac output, cardiac index (CI), central venous pressure, 


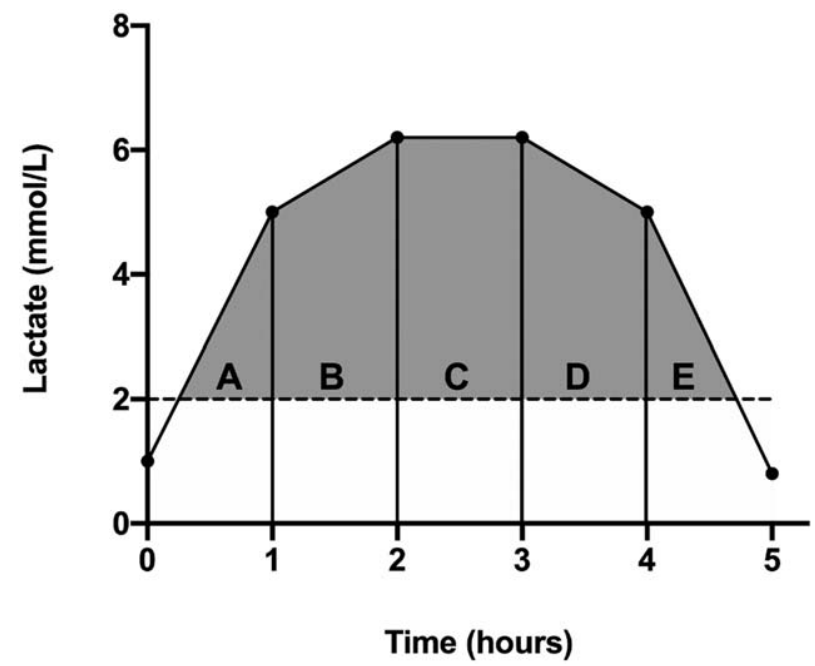

FIG. 1. The lactate area under the curve (AUC) above the upper normal limit of lactate $(2.0 \mathrm{mmol} / \mathrm{L})$ was calculated using the trapezoidal method based on five possible scenarios depicted in (A-E).

pulmonary artery pressure, and mixed venous oxygen saturation were continuously monitored using a pulmonary artery catheter (Edwards Lifesciences LLC, Irvine, Calif). Arterial blood pressure was measured using a standard invasive arterial line. Arterial blood gas samples were obtained hourly for the first $6 \mathrm{~h}$ after ICU admission. Blood samples drawn into a commercial, preheparinized $1 \mathrm{~mL}$ arterial blood sampler were then immediately analyzed by an ABL90 FLEX automatic blood gas analyzer (Radiometer America Inc, Brea, Calif). Hemoglobin, hematocrit, $\mathrm{pH}, \mathrm{PaO}_{2}, \mathrm{PaCO}_{2}$, and glucose were also reported on each blood gas analysis. After $6 \mathrm{~h}$, blood gas analysis was performed as needed by the clinical team.

\section{Lactate levels and the lactate area under the curve (AUC)}

The severity of hyperlactatemia during the first $6 \mathrm{~h}$ of the patient's ICU stay was calculated using the trapezoidal method, which assumed a linear change between measurements over time to estimate the intensity of blood lactate concentration $>2.0 \mathrm{mmol} / \mathrm{L}$ (incorporating both depth and time) (Fig. 1) (19). Lactate measurements were no longer recorded if the patient achieved lactate normalization (lactate $\leq 2.0 \mathrm{mmol} / \mathrm{L}$ ) prior to $6 \mathrm{~h}$. Lactate normalization was defined as the duration of time between ICU arrival and the first lactate concentration $\leq 2 \mathrm{mmol} / \mathrm{L}$.

\section{Microcirculatory imaging and analysis}

Evaluation of microcirculation was recorded using sublingual incident dark field video microscopy (CytoCam, Braedius Medical BV, The Netherlands) upon arrival to the ICU by JCG (20). Images were obtained by gently placing the videomicroscope under the tongue until an adequate view of the microcirculation was in view. A minimum of three video clips of $5 \mathrm{~s}$ (100 frames) duration were included at each time point per analysis, with attention to quality factors, especially the absence of pressure artefact, excess saliva, and proper location in accordance with the accepted consensus for assessing the microcirculation (Fig. 2). Averaging $\geq 3$ videos improves reproducibility of sublingual microcirculation imaging (21).

Each clip was deidentified and coded to be analyzed after enrollment was complete. Microcirculatory videos were exported to Automated Vascular Analysis (AVA 3.2; Microvision Medical B.V.) format using the CCTools 2 software to be manually analyzed using a validated, web-based tool (22). Video analysis was performed at the conclusion of the data collection period by the lead investigator (JCG) and AES who were blinded to the conditions of the subject. Image quality was assessed using the 6-factor Massey quality score, which scores each video for appropriate illumination, duration, focus, content, stability, and pressure. Images were only analyzed if the Massey quality score was $<10(23)$. Only microvessels $<20 \mu \mathrm{m}$ in diameter were included in the analysis. Vessel-by-vessel microcirculatory flow index (MFIv), microcirculatory heterogeneity index (MHI), total vessel density (TVD), proportion of perfused vessels (PPV), perfused vessel density (PVD) were manually measured according to the current best practice guidelines for reporting microcirculatory variables (24). A description of the microcirculation characteristics measured is included in Table 1. Blood flow within each microvessel was graded using a semiquantitative scale, based on the vascular flow pattern ranging from 0 to $3(0=$ no flow, $1=$ intermittent, $2=$ sluggish, or $3=$ continuous flow). We considered vessels with no flow or intermittent flow as nonperfused, whereas continuous or sluggish scores were regarded as perfused vessels for the calculation of PPV and PVD. Microcirculatory impairment was defined as an MFI $<2.6$, MHI $>0.4$, PVD $<18 \mathrm{~mm} / \mathrm{mm}^{2}$ $(15,25,26)$.

\section{Intensive care unit resuscitation and management}

All patients were warmed to $36^{\circ} \mathrm{C}$ using a forced-air warming blanket as needed. Initial resuscitation to normalize systemic hemodynamics, including adequate intravascular filling pressures, mean arterial pressure (MAP) of $65 \mathrm{~mm} \mathrm{Hg}$ to $80 \mathrm{~mm} \mathrm{Hg}$, cardiac index of $>2.2 \mathrm{~L} / \mathrm{min} / \mathrm{m}^{2}$, was targeted unless specified by the surgical team. Perfusion targets included a mixed venous oxygen saturation $>65 \%$ and lactate normalization. After adequate intravascular volume resuscitation, phenylephrine was titrated to achieve the patient's goal MAP and epinephrine was titrated to achieve an adequate cardiac index. A standard postoperative hemoglobin target of $8 \mathrm{~g} / \mathrm{dL}$ was established for packed red blood cell transfusion.

\section{Availability of data and materials}

The dataset supporting the conclusions of this article is available via the Zenodo research data repository (27).

\section{Statistical analysis}

Data were assessed for normality using the D'Agostino and Pearson omnibus normality test. Global hemodynamic and microcirculation variables are
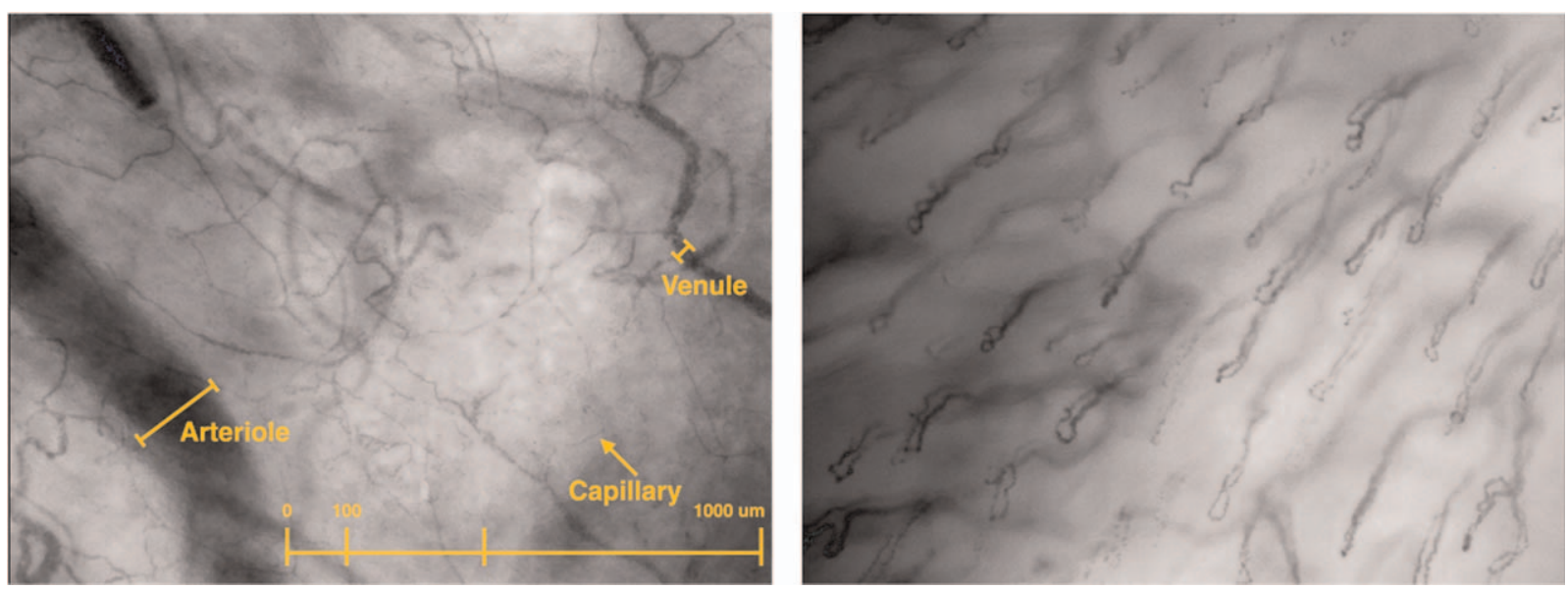

FIG. 2. Example of high-quality video sequence accepted for analysis (left). Example of video not analyzed due to poor quality score ( $>25 \%$ vessel loops, improper anatomic location). 
TABLE 1. Description of microcirculation variables measured by incident dark field microscopy (IDF)

Variable (Abbreviation, units)

Definition and characteristics

Microvascular flow index (vessel-by-vessel) (MFIv, arbitrary units)

Microcirculation heterogeneity index (MHI, arbitrary units)

Proportion of perfused vessels (PPV, \%)

Total vessel density (TVD, $\mathrm{mm} / \mathrm{mm}^{2}$ )

Perfused vessel density (PVD, $\mathrm{mm} / \mathrm{mm}^{2}$ )
Individual microvessels ( $<20$ um diameter) are assigned a semiquantitative flow value of no flow (0), intermittent flow (1), sluggish flow (2), or continuous flow (3). The overall score for each video is the average of the individual values.

Coefficient of variation calculated using the quadrant-based MFI scores. Equals the (highest lowest value)/mean. Evaluates the distribution and variability of flow within the field of view.

Percentage of the total microcirculatory vessel length with flow grades that met accepted threshold (sluggish or continuous).

Measurement of total vessel area per surface area. Determinant of capillary distance to tissue (diffusive capacity).

PPV $\times$ TVD. Estimates the functional capillary density, which accounts for both convective and diffusive properties of the visualized microcirculatory bed. reported as mean $\pm \mathrm{SD}$. Variables that were not normally distributed are reported as median with interquartile range (25th-75th percentiles). Differences between normally distributed variables were assessed using paired Student $t$ test or Wilcoxon matched-pairs signed rank test. Non-normal data were compared using Mann-Whitney $U$ test. Two-way ANOVA with Sidak post-hoc testing for multiple comparisons was performed to compare hourly postoperative lactate levels grouped by quantitative microcirculatory thresholds along with other variables recorded over time. BlandAltman plot was performed for $10 \%$ of videos to assess interrater reliability between coders. Statistical analysis was conducted using Prism v 8.0 (GraphPad Software, San Diego, Calif). Statistical significance was assumed at $P<0.05$.

\section{RESULTS}

\section{Baseline characteristics and physiologic data}

During the study period we enrolled 53 patients receiving elective cardiac surgery who fulfilled the inclusion criteria. Three subjects were excluded due to inadequate microcirculatory video quality scores, which left 50 patients for final analysis. Baseline demographic, surgical, and intraoperative data are included in Table 2. Selected hourly postoperative resuscitation intervention data are included in Supplement Figure 1, http://links.lww.com/SHK/B195. All patients survived to hospital discharge.

\section{Microcirculation video and quality data}

A total of 218 microcirculation video clips were screened for quality and 165 video clips met the threshold for further analysis. JCG analyzed 125 videos, AED analyzed 40 videos, and 20 were analyzed by both investigators to determine interrater agreement. Total median Massey score was 0 [01]. Massey component scores included illumination 0 [0-0], duration $0[0-0]$, focus $0[0-0]$, content $0[0-0]$, stability $0[0-$ $0]$, and pressure 0 [0-0]. Cohen kappa for inter-rater agreement was $\kappa=0.95$, bias was $0.1 \pm 1.4[-2.5-2.8]$. Frequency of microcirculation abnormalities are shown in Figure 3.

TABLE 2. Subject characteristics, demographics, and perioperative data

\begin{tabular}{|c|c|c|c|c|c|}
\hline & $\begin{array}{l}\text { All subjects } \\
n=50\end{array}$ & $\begin{array}{c}\mathrm{MHI} \leq 0.4 \\
\mathrm{n}=30\end{array}$ & $\begin{array}{c}\mathrm{MHI}>0.4 \\
\mathrm{n}=20\end{array}$ & $\begin{array}{c}\text { PVD } \geq 18 \\
n=37\end{array}$ & $\begin{array}{c}\text { PVD }<18 \\
n=13\end{array}$ \\
\hline Age, y & $64 \pm 12$ & $63 \pm 13$ & $66 \pm 10$ & $63 \pm 12$ & $68 \pm 10$ \\
\hline Sex, male & $32(64)$ & $14(47)$ & $18(9)$ & $21(57)$ & $11(85)$ \\
\hline euroSCORE II & $1.5[0.78-2.8]$ & $1.8[0.8-3.3]$ & $1.5[0.8-2.0]$ & $1.5[0.8-2.8]$ & $1.6[0.8-2.8]$ \\
\hline \multicolumn{6}{|l|}{ Performed operation } \\
\hline Coronary artery bypass grafting (CABG) & $20(40)$ & $13(43)$ & $7(35)$ & $17(46)$ & $4(31)$ \\
\hline CABG + valve Replacement/repair & $11(22)$ & $6(20)$ & $5(25)$ & 7 (19) & $4(31)$ \\
\hline Valvular surgery only & $19(38)$ & $11(37)$ & $8(40)$ & $13(35)$ & $6(46)$ \\
\hline \multicolumn{6}{|l|}{ Comorbidities } \\
\hline Hypertension & $42(84)$ & $24(80)$ & $18(90)$ & $32(86)$ & $10(77)$ \\
\hline Diabetes & $18(32)$ & $11(37)$ & 7 (35) & $17(46)$ & $1(8)^{*}$ \\
\hline Heart failure with reduced EF $(<30 \%)$ & $10(8)$ & $7(23)$ & $3(15)$ & $8(22)$ & $2(15)$ \\
\hline Chronic kidney disease & $8(20)$ & $6(25)$ & $2(8)$ & 7 (19) & $1(8)$ \\
\hline \multicolumn{6}{|l|}{ Intraoperative details } \\
\hline Cardiopulmonary bypass time, min & $93[75-129]$ & $88[75-116]$ & $112[75-141]$ & $88[74-116]$ & $114[78-146]$ \\
\hline Cross-clamp time, $\min$ & $72[51-95]$ & $69[48-87]$ & $83[54-104]$ & $66[49-88]$ & $84[59-116]$ \\
\hline Grafts (CABG patients), $\mathrm{n}$ & $3[2-3]$ & $3[2-3]$ & $3[2-3]$ & $3[2-3]$ & $3[2-3]$ \\
\hline Cell saver transfusion, $\mathrm{mL}$ & $600[450-900]$ & $500[450-675]$ & $850[463-987]$ & $600[450-900]$ & $575[450-900]$ \\
\hline $\mathrm{RBC}$ transfusion, $\mathrm{n}$ units & $0[0-3]$ & $14[1-4]$ & $7 ;[2-3]$ & $16 ; 3[2-4]$ & $5 ; 3[3-7]$ \\
\hline FFP transfusion, $\mathrm{n}$ units & $0[0-0]$ & $7 ; 2[1-3]$ & $4 ; 1.5[1-5]$ & $7 ; 1[1-2]$ & $3 ; 2[1-6]$ \\
\hline Platelet transfusion, $\mathrm{n}$ units & $0[0-1]$ & $12[1-1]$ & $4 ; 1.5[1-5]$ & $10 ; 1[1-1]$ & $5 ; 2[1-3]$ \\
\hline Crystalloid intravenous fluid, $L$ & $1.0[0.7-1.5]$ & $1.1 \pm 0.7$ & $1.4 \pm 0.9$ & $1.0 \pm 0.6$ & $1.7 \pm 1.1^{\star}$ \\
\hline Urine output, $\mathrm{mL}$ & $675[450-1163]$ & $848 \pm 715$ & $955 \pm 618$ & $851 \pm 687$ & $1,005 \pm 642$ \\
\hline CPB ultrafiltrate, $\mathrm{mL}$ & $0[0-475]$ & $0[0-700]$ & $0[0-0]$ & $0[0-700]$ & $0[0-0]$ \\
\hline
\end{tabular}

Data presented as mean \pm standard deviation, median [quartile range], and frequency (\%).

${ }^{*} P<0.05$ 


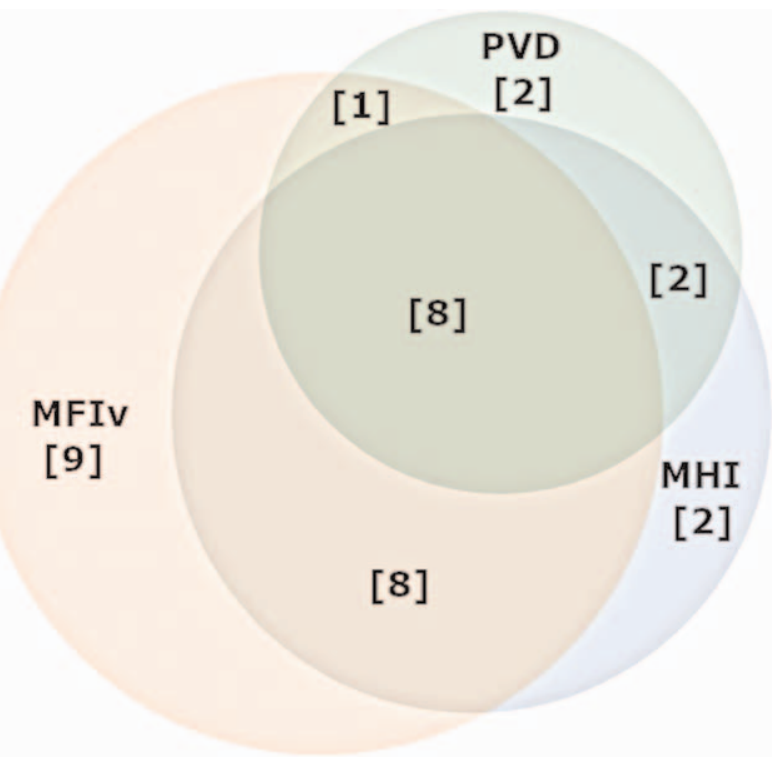

FIG. 3. Frequency of microcirculatory derangements in subjects with abnormal postoperative microcirculation.

\section{Postoperative lactate and microcirculation}

Nine subjects $(18 \%)$ presented to the ICU with an initial lactate of $2.0 \mathrm{mmol} / \mathrm{L}$ or less and never developed an abnormal lactate level. A total of 332 lactate measurements were included in the analysis. Median lactate concentration at ICU arrival was
$3.0[1.7-4.1] \mathrm{mmol} / \mathrm{L}$; minimum $0.8 \mathrm{mmol} / \mathrm{L}$ and maximum $8.1 \mathrm{mmol} / \mathrm{L}$. Sixteen subjects $(32 \%)$ achieved lactate normalization within $6 \mathrm{~h}$.

Microcirculation-heterogeneity-Twenty subjects (40\%) had high microcirculatory heterogeneity (MHI) on admission. Physiologic and ICU resuscitation data on admission and $6 \mathrm{~h}$ postadmission are reported in Table 3. Lactate kinetics over the first $6 \mathrm{~h}$ are shown in Figure 4. There was no difference between admission lactate at the time of microcirculation measurement $(2.7 \pm 1.6$ vs. $3.5 \pm 1.8 \mathrm{mmol} / \mathrm{L} ; P=0.09)$ between subjects with a normal and high MHI on admission. Peak lactate $(6.0 \pm 3.1$ vs. $3.9 \pm 2.2 \mathrm{mmol} / \mathrm{L} ; P<0.001$ ) was higher in the high MHI group, and time to lactate normalization was longer in the high MHI group ( $9.8 \pm 4.4$ vs. $7.0 \pm 4.8 \mathrm{~h} ; P<0.05)$. PPV was higher in the high MHI group $(79.1 \pm 6.2 \%$ vs. $88.6 \pm 6.1 \% ; P<0.001)$ than in the normal MHI group. TVD was not significantly different between groups ( $22.4 \pm 3.9 \%$ vs. $24.2 \pm 3.7 \% ; P=0.1)$.

Microcirculation-perfused vessel density-Thirteen subjects $(26 \%)$ presented to the ICU with low microcirculatory PVD. Intensive care unit physiologic and resuscitation data on admission and $6 \mathrm{~h}$ postadmission are reported in Table 4 . Lactate kinetics over the first $6 \mathrm{~h}$ are shown in Figure 5. Admission lactate at the time of microcirculation measurement $(4.2 \pm 1.9$ vs. $2.6 \pm 1.4 \mathrm{mmol} / \mathrm{L} ; P<0.01)$ and peak lactate $(7.2 \pm 2.5$ vs. $3.8 \pm 2.3 \mathrm{mmol} / \mathrm{L} ; P<0.0001)$ were higher in patients with low PVD compared with those with a normal postoperative PVD. Time to lactate normalization was longer in the low PVD group $(11.3 \pm 1.6$ vs. $7.0 \pm 5.0 \mathrm{~h} P<0.01)$. Both

TABLE 3. Physiologic and ICU resuscitation data by MHI

\begin{tabular}{|c|c|c|c|c|}
\hline & $\mathrm{MHI} \leq 0.4 \mathrm{t}_{0}$ & $\mathrm{MHI}>0.4 \mathrm{t}_{0}$ & $\mathrm{MHI} \leq 0.4 \mathrm{t}_{6}$ & $\mathrm{MHI}>0.4 \mathrm{t}_{6}$ \\
\hline \multicolumn{5}{|l|}{ Clinical and macrocirculatory data } \\
\hline Temperature, ${ }^{\circ} \mathrm{C}$ & $36.1 \pm 0.7$ & $36.3 \pm 0.8$ & $37.5 \pm 0.7$ & $37.3 \pm 0.8$ \\
\hline Heart rate, bpm & $82 \pm 17$ & $85 \pm 9$ & $87 \pm 14$ & $89 \pm 13$ \\
\hline Mean arterial pressure, $\mathrm{mm} \mathrm{Hg}$ & $77 \pm 9$ & $74 \pm 11$ & $77 \pm 12$ & $76 \pm 10$ \\
\hline Central venous pressure, $\mathrm{mm} \mathrm{Hg}$ & $9 \pm 4$ & $11 \pm 4$ & $7 \pm 4$ & $7 \pm 5$ \\
\hline Cardiac index, $\mathrm{L} / \mathrm{min} \cdot \mathrm{m}^{2}$ & $2.4 \pm 0.8$ & $2.2 \pm 0.5$ & $2.6 \pm 0.6$ & $2.7 \pm 0.7$ \\
\hline SVRi, dyn.s. $\mathrm{cm}^{-5} \cdot \mathrm{m}^{2}$ & $2,473 \pm 988$ & $2,422 \pm 708$ & $2,189 \pm 561$ & $2,169 \pm 495$ \\
\hline \multicolumn{5}{|l|}{ Laboratory data } \\
\hline Hemoglobin, g/dL & $12.1 \pm 1.6$ & $13.1 \pm 1.5^{\star}$ & $11.9 \pm 1.3$ & $12.4 \pm 1.9$ \\
\hline Hematocrit, \% & 37 [34-39] & $41[36-43]^{\star}$ & 37 [31-39] & $38[35-41]$ \\
\hline $\mathrm{pH}$ & $7.31[7.29-7.37]$ & $7.31[7.27-7.33]$ & $7.35[7.31-7.4]$ & $7.36[7.31-7.39]$ \\
\hline $\mathrm{PaO}_{2}, \mathrm{~mm} \mathrm{Hg}$ & $149[94-250]$ & $176[113-269]$ & $109[86-116]$ & $105[86-142]$ \\
\hline $\mathrm{PCO}_{2}, \mathrm{~mm} \mathrm{Hg}$ & $41[36-45]$ & $43[40-47]$ & $41[37-45]$ & $36[33-41]^{\dagger}$ \\
\hline Mixed venous $\mathrm{O}_{2}$ saturation, \% & $72[67-76]$ & $73[62-80]$ & $67[63-71]$ & $65[60-72]$ \\
\hline Glucose, g/dL & $154 \pm 33$ & $163 \pm 30$ & $150 \pm 34$ & $157 \pm 32$ \\
\hline \multicolumn{5}{|l|}{ Volume resuscitation (first 6 h) } \\
\hline Intravenous crystalloid, L & - & - & $1.4 \pm 0.9$ & $1.7 \pm 0.8$ \\
\hline RBC transfusion, $n$ patients; units & - & - & $3 ; 1[1-2]$ & $3 ; 3[2-3]$ \\
\hline FFP transfusion, $\mathrm{n}$ patients; units & - & - & $3 ; 2[2-2]$ & $3 ; 2[1-4]$ \\
\hline Platelet transfusion, $\mathrm{n}$ patients; units & - & - & $2 ; 2[2-2]$ & $1 ; 2[2-2]$ \\
\hline Urine output, $\mathrm{mL}$ & - & - & $610 \pm 360$ & $600 \pm 240$ \\
\hline Blood loss, mL & - & - & $170[110-300]$ & $290[160-370]$ \\
\hline 6-h volume balance & - & - & $(+) 690 \pm 870$ & (+) $1,050 \pm 820$ \\
\hline \multicolumn{5}{|l|}{ Vasopressor support } \\
\hline Phenylephrine, $\mathrm{n}$ patients (\%) $\mathrm{mcg} / \mathrm{kg} / \mathrm{min}$ & $10(33) 0.6[0.4-1.0]$ & $3(15) 0.5[0.3-0.6]$ & $11(37) 0.8[0.5-1.0]$ & 7 (35) $0.8[0.5-1.1]$ \\
\hline
\end{tabular}

Inotropic support

Epinephrine, $\mathrm{n}$ patients (\%) $\mathrm{mcg} / \mathrm{kg} / \mathrm{min} \quad 24$ (80) 0.04 [0.02-0.07] 14 (70) 0.03 [0.02-0.05] 21 (70) 0.02 [0.01-0.04] 14 (70) 0.04 [0.02-0.06]

Data presented as mean \pm standard deviation, median [quartile range], and frequency (\%).

${ }^{*} P<0.05$.

${ }^{\dagger} P<0.01$.

$\mathrm{MHI}$ indicates microcirculatory heterogeneity index; T0, ICU admission; T6, 6 hours after ICU admission. 


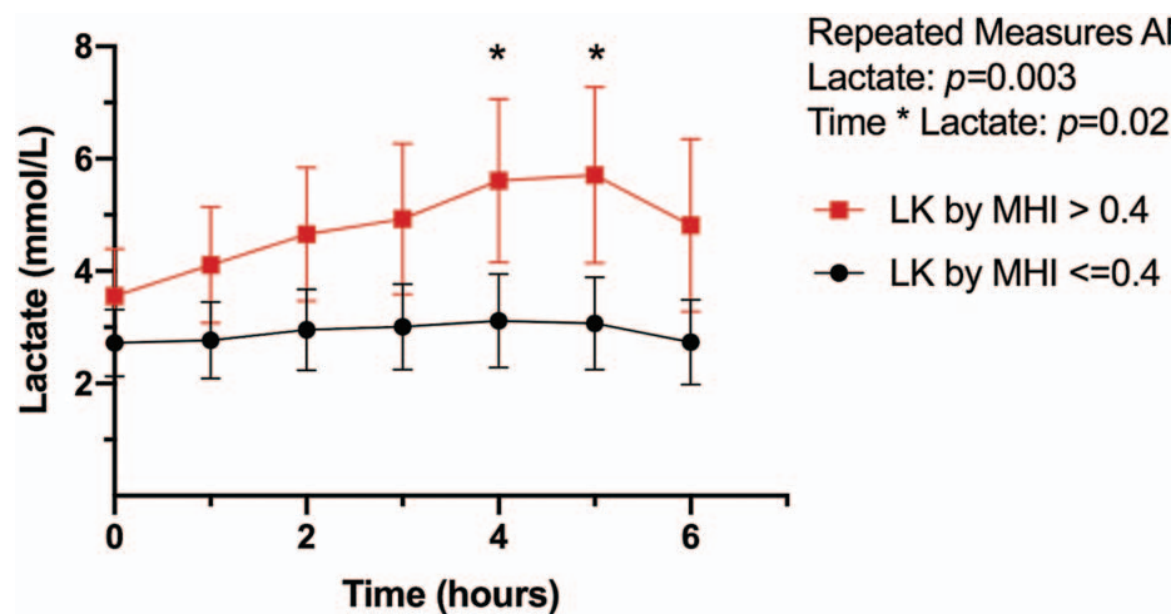

FIG. 4. Lactate kinetics by postoperative MHI measured at ICU admission. Hourly mean lactate with (with $95 \% \mathrm{Cl}$ ) shown. Intergroup difference * $P<0.05$. MHI indicates microcirculatory heterogeneity index; ICU, intensive care unit.

PPV $(78.8 \pm 6.8 \%$ vs. $86.6 \pm 7.0 \% ; P<0.001)$ and TVD $(19.1 \pm 2.6$ vs. $25.1 \pm 2.9 P<0.0001)$ were reduced in the low PVD group.

Microcirculation-microvascular flow index-Twenty-six subjects $(52 \%)$ had a low MFIv on admission. Lactate kinetics over the first $6 \mathrm{~h}$ are shown in Figure 6. There were no differences in lactate concentration at any time point between those with normal or abnormal MFIv. There was no difference in demographics, intraoperative data, intraoperative resuscitation, or postoperative resuscitation characteristics between subjects with a normal versus low MFIv when measured on admission to the ICU. There was no difference between admission lactate at the time of microcirculation measurement $(2.9 \pm 1.4 \mathrm{vs}$. $3.2 \pm 1.9 \mathrm{mmol} / \mathrm{L} ; P=0.43)$ and peak lactate $(4.2 \pm 2.4$ vs. $5.2 \pm 3.0 \mathrm{mmol} / \mathrm{L} ; P=0.23$ ) between normal and low MFIv groups. There was no difference in lactate normalization

TABLE 4. Physiologic and ICU resuscitation data by PVD $\left(\mathrm{mm} / \mathrm{mm}^{2}\right)$

\begin{tabular}{|c|c|c|c|c|}
\hline & $P V D \geq 18 t_{0}$ & $P V D<18 t_{0}$ & $P V D \geq 18 t_{6}$ & $\mathrm{PVD}<18 \mathrm{t}_{6}$ \\
\hline \multicolumn{5}{|l|}{ Clinical and macrocirculatory data } \\
\hline Temperature, ${ }^{\circ} \mathrm{C}$ & $36.1 \pm 0.8$ & $36.6 \pm 0.5$ & $37.2 \pm 11.6$ & $37.6 \pm 0.7$ \\
\hline Heart rate, bpm & $82 \pm 15$ & $84 \pm 12$ & $89 \pm 13$ & $83 \pm 13$ \\
\hline Mean arterial pressure, $\mathrm{mm} \mathrm{Hg}$ & $77 \pm 10$ & $73 \pm 9$ & $76 \pm 11$ & $77 \pm 11$ \\
\hline Central venous pressure, $\mathrm{mm} \mathrm{Hg}$ & $10 \pm 4$ & $12 \pm 5$ & $7 \pm 4$ & $9 \pm 5$ \\
\hline Cardiac index, $\mathrm{L} / \mathrm{min} \cdot \mathrm{m}^{2}$ & $2.4 \pm 0.8$ & $2.2 \pm 0.5$ & $2.7 \pm 0.6$ & $2.5 \pm 0.7$ \\
\hline SVRi, dyn.s.cm $\mathrm{cm}^{-5} \cdot \mathrm{m}^{2}$ & $2,508 \pm 956$ & $2,283 \pm 594$ & $2,118 \pm 510$ & $2,337 \pm 562$ \\
\hline \multicolumn{5}{|l|}{ Laboratory data } \\
\hline Hemoglobin, g/dL & $12.4 \pm 1.6$ & $12.6 \pm 1.8$ & $12.1 \pm 1.3$ & $12.0 \pm 2.3$ \\
\hline Hematocrit, \% & 39 [35-41] & $40[34-42]$ & 37 [33-39] & $38[29-40]$ \\
\hline $\mathrm{pH}$ & $7.31[7.28-7.36]$ & $7.32[7.29-7.36]$ & $7.36[7.31-7.38]$ & $7.37[7.33-7.41]$ \\
\hline $\mathrm{PaO}_{2}, \mathrm{~mm} \mathrm{Hg}$ & $151[101-265]$ & $160[107-245]$ & $111[83-143]$ & $104[92-117]$ \\
\hline $\mathrm{PCO}_{2}, \mathrm{~mm} \mathrm{Hg}$ & $42[39-45]$ & $48[45-60]^{\dagger}$ & $40[36-45]$ & $36[33-42]$ \\
\hline Mixed venous $\mathrm{O}_{2}$ saturation, $\%$ & $73[67-76]$ & $75[62-79]$ & $67[64-72]$ & $64[59-69]$ \\
\hline Glucose, g/dL & $154 \pm 34$ & $168 \pm 24$ & $155 \pm 34$ & $147 \pm 31$ \\
\hline \multicolumn{5}{|l|}{ Volume resuscitation (first $6 \mathrm{~h}$ ) } \\
\hline Intravenous crystalloid, L & - & - & $1.3[0.8-2.0]$ & $1.8[1.1-2.3]$ \\
\hline $\mathrm{RBC}$ transfusion, $\mathrm{n}$ patients; units & - & - & $3 ; 1[1-3]$ & $3 ; 2[2-3]$ \\
\hline FFP transfusion, $\mathrm{n}$ patients; units & - & - & $4 ; 2[1-2]$ & $2 ; 3[2-4]$ \\
\hline Platelet transfusion, $\mathrm{n}$ patients; units & - & - & $1 ; 2[2-2]$ & $2 ;[2-2]$ \\
\hline Urine output, $\mathrm{mL}$ & - & - & $610 \pm 330$ & $590 \pm 290$ \\
\hline Blood loss, $\mathrm{mL}$ & - & - & $200[120-310]$ & $290[140-390]$ \\
\hline 6 -h volume balance & - & - & $(+) 700 \pm 830$ & (+) $1,200 \pm 890$ \\
\hline \multicolumn{5}{|l|}{ Vasopressor support } \\
\hline Phenylephrine, $\mathrm{n}$ patients $(\%) ; \mathrm{mcg} / \mathrm{kg} / \mathrm{min}$ & $11(30) 0.6[0.3-1.0$ & $2(15) 0.5[0.5-0.5]$ & $14(38) 0.6[0.5-1.1]$ & 4 (31) 0.9 [0.8-0.9] \\
\hline \multicolumn{5}{|l|}{ Inotropic support } \\
\hline Epinephrine, n patients (\%) $\mathrm{mcg} / \mathrm{kg} / \mathrm{min}$ & 29 (78) $0.03[0.02-0.05]$ & 9 (69) 0.06 [0.02-0.07] & $26(70) 0.02[0.01-0.04]$ & 9 (69) 0.03 [0.01-0.09] \\
\hline
\end{tabular}

Data presented as mean \pm standard deviation, median [quartile range], and frequency (\%).

${ }^{\dagger} P<0.01$.

PVD indicates perfused vessel density; T0, ICU admission; T6, 6 hours after ICU admission. 


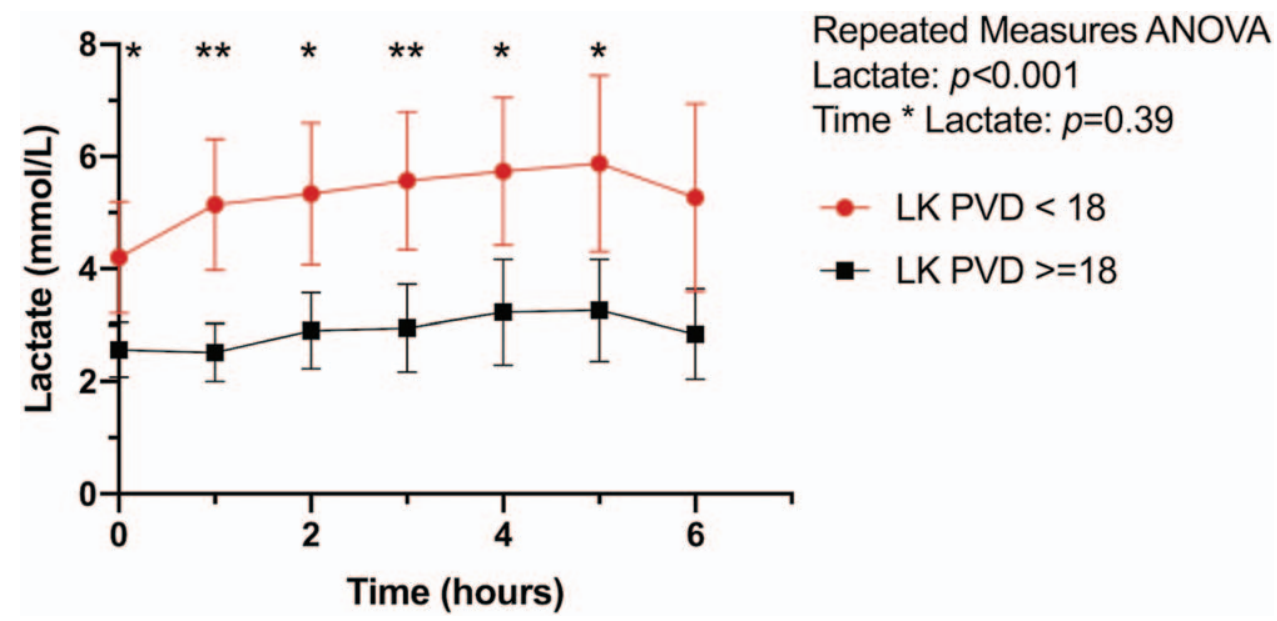

FIG. 5. Lactate kinetics by postoperative PVD measured at ICU admission. Hourly mean lactate with (with $95 \% \mathrm{Cl}$ ) shown. Intergroup difference ${ }^{*} P<0.05,{ }^{* *} P<0.01$. PVD indicates perfused vessel density; ICU, intensive care unit.

between normal and low MFIv groups $(7.3 \pm 5.0$ vs. $8.8 \pm$ $4.6 \mathrm{~h} ; P=0.26)$.

Lactate area under the curve-When grouped by predefined cutoffs for abnormal postoperative microcirculation, patients with high heterogeneity had an increased lactate AUC compared with those with low heterogeneity $(2.5[0.1-8.2]$ vs. 13.1 [3.7-31.1]; $P<0.001)$. Patients with low PVD had an increased lactate AUC compared with those with a normal PVD (22.3 [9.4-31.0] vs. $2.6[0-8.8] ; P<0.0001)$. There was no difference in lactate AUC in subjects with normal versus low MFIv (Fig. 7).

\section{DISCUSSION}

This is the first study to examine the relationship between early microcirculatory derangements and the intensity of hyperlactatemia over time in critically ill patients after cardiac surgery. We were able to demonstrate that early impairment of microcirculatory perfused vessel density and high heterogeneity are associated with increased lactate concentration and duration compared with patients with normal postoperative microcirculation during the first $6 \mathrm{~h}$ of resuscitation. We also found that early impairment of vessel-by-vessel microvascular flow index was not associated with an increased lactate AUC during the first $6 \mathrm{~h}$ of postoperative resuscitation.

Resuscitation thresholds based on microcirculatory blood flow to guide therapeutic intervention are of significant interest (28). Commonly used physical examination-based and laboratory-based thresholds such as capillary refill time, $\mathrm{PvaCO}_{2}$, $\mathrm{ScvO}_{2}$, and lactate can provide important clinical insight, but each has their limitations. The role of lactate in critical illness has been widely studied but remains incompletely understood. Lactate can rise from a number of nonischemic causes, including the administration of exogenous catecholamines causing $\beta_{2}$ stimulation, inadequate tissue oxygen uptake, increased glycolysis, or decreased hepatic clearance $(5,6,29)$. In our study groups, there did not appear to be a difference in postoperative liver function tests, glucose concentration, or catecholamine administration between normal versus impaired microcirculation groups.

The presence and diversity of microcirculatory derangements found in our post-cardiac surgery cohort (Fig. 3) highlight the limitations of our traditional approach to shock, which

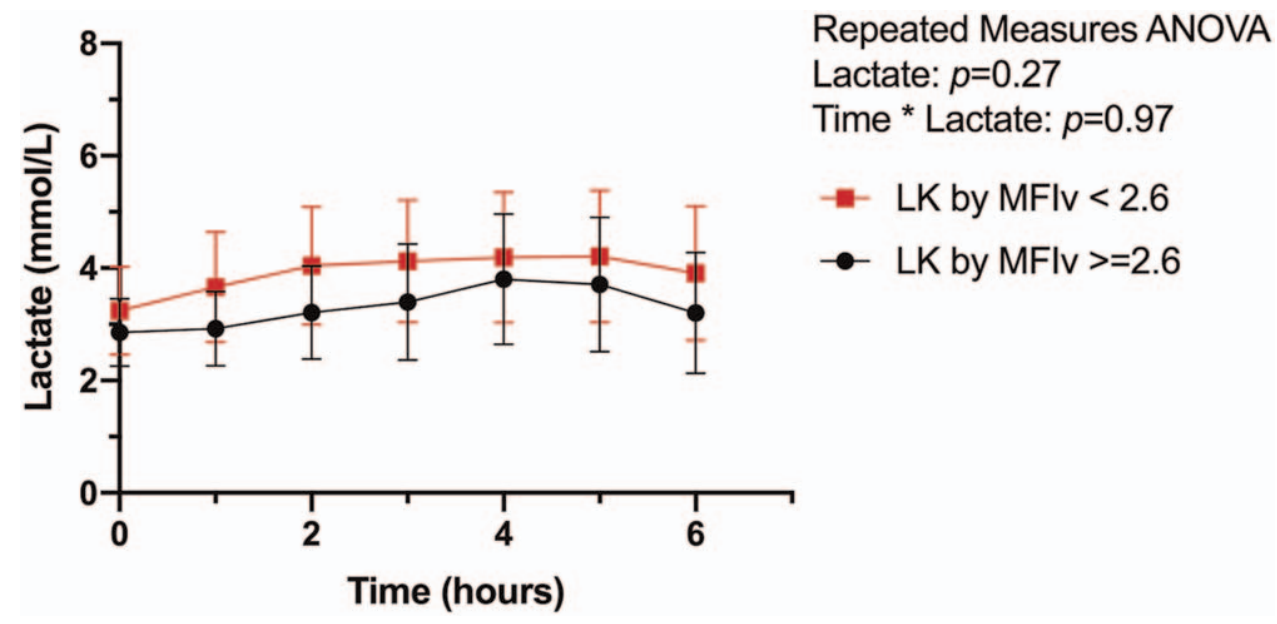

FIG. 6. Lactate kinetics by postoperative MFIv measured at ICU admission. Hourly mean lactate with (with $95 \% \mathrm{Cl}$ ) shown. 


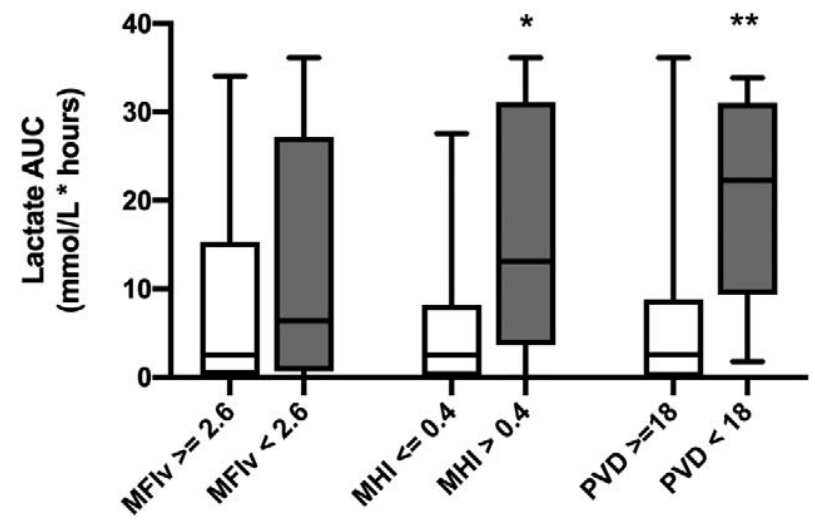

FIG. 7. Lactate area under the curve by postoperative microcirculation abnormality. Boxes show median, interquartile range (whiskers representing minimum/maximum values) ${ }^{*} P<0.01,{ }^{* *} P<0.001$.

is often classified by macrocirculatory phenotypes (e.g., hypovolemic, distributive, cardiogenic, etc). Handheld video microscopy can provide detailed information regarding patient-specific perfusion abnormalities such as microcirculatory shunting, changes in red blood cell velocity, and reduced capillary density. Our patients all achieved appropriate hemodynamic goals, indicating a clear dissociation between the macro- and microcirculation in a large proportion of patients. The high lactate AUC in subjects with a low functional capillary density $\left(\mathrm{PVD}<18 \mathrm{~mm} / \mathrm{mm}^{2}\right.$ ) and high heterogeneity $(\mathrm{MHI}>0.4)$ indicates an increased intensity of cellular hypoxia that occurred during the first $6 \mathrm{~h}$ of resuscitation. This is an important finding, as traditional resuscitation strategies applied to patients with postoperative shock such as intravenous fluid administration, vasopressors, nitric oxide donors, anticoagulants, or anti-inflammatory agents may provide greater patient benefit if used to target microcirculation-specific derangements $(30,31)$.

Perfused vessel density provides an estimate of functional capillary density, reflecting a combination of microcirculation diffusive and convective properties. Patients with a reduced PVD developed a higher peak lactate as well as a prolonged duration of lactic acidosis. These findings were independent of differences in systemic hemodynamics, hematocrit, glucose concentration, liver function, catecholamine dose, and other contributors toward lactate generation and clearance. Several studies have found that reductions in PVD are associated with an elevation in blood lactate concentration at the time of measurement $(15,32,33)$. Previous studies have identified decreases in functional capillary density after cardiac surgery, but our findings link the loss of PVD as a mechanistic cause for prolonged lactic acidosis $(3,34)$. The high lactate AUC in patients with low PVD may be the result of microthrombosis, reduced tissue diffusive capacity, or microvascular shunting leading to a prolonged cytosolic redox state and impaired tissue oxygenation.

Patients with a high microcirculation heterogeneity also experienced a higher peak lactate and a greater lactate AUC. Increases in heterogeneity have been identified in patients with sepsis, ischemia-reperfusion injury, and after cardiac surgery
$(3,14,35)$. Causes for increased flow variation in localized microvascular beds include systemic inflammation, changes in local nitric oxide release, and vascular endothelial injury which are not rapidly reversible (36). Heterogeneous capillary blood flow represents a second mechanism of prolonged postoperative lactic acidosis, where an increase in flow through a reduced number of capillaries results in decreased red blood cell oxygen offloading and regional tissue hypoxia $(37,38)$. It appears to cause more severe alterations in tissue oxygenation compared with homogenously decreased perfusion $(39,40)$. Interestingly, 10 of the 13 subjects with reduced PVD also had an increased MHI. The cumulative effect of both impaired convective blood flow and diffusive capacity may explain the larger lactate AUC seen in the low PVD group.

Of all the measurements obtained with handheld video microscopy on the microcirculation, MFIv is the most subjective as it relies on the reviewer to assign a semiquantitative score to each capillary, which reduces its sensitivity for convective impairments. This may explain why we did not find an association between MFIv and postoperative lactate AUC. Rapid analysis that reports objective measures such as RBC velocity has remained one of the largest barriers to objectively classifying convective flow abnormalities and incorporating HVM into clinical care, but there is promising data that may allow clinical adoption of this technology in the near future (41, 42).

Several limitations should be discussed. First, we performed sublingual IDF microscopy to assess postoperative microcirculatory function, which may not represent global capillary blood flow. Sublingual IDF correlates with gut and renal microcirculation in patients with circulatory shock, but discrepancies between individual organ systems can exist $(43,44)$. Second, we are reporting microcirculatory characteristics within a single cohort of patients with circulatory shock after cardiac surgery. Our methods did not include a baseline measurement prior to patients receiving cardiac surgery. Pragmatically, clinicians are often faced with receiving critically ill patients without a known patient-specific baseline function, which may lead to under- or over-resuscitation. Determination of abnormal microcirculation thresholds for a population as well as patientspecific microcirculatory capacity are an important next step for research. Topical agents have been used to identify an individual's microcirculatory capacity, and have been tied to functional outcomes (45). Further investigation to explore this relationship in critically ill patients may provide insight toward setting patient-specific resuscitation targets in the future. Our dataset was not powered to show the independent effect of isolated changes in microcirculatory blood flow characteristics. Although controlled experiments have shown increased heterogeneity may impact tissue hypoxia more than a uniform decrease in blood flow, these findings need to be examined more closely in a human model. Lastly, multiple studies have found a prolonged $(>6 \mathrm{~h})$ duration of microcirculation abnormalities after cardiac surgery independent of systemic hemodynamics. We did not perform serial microcirculation measurements on our subjects. Relative changes from baseline and over time would strengthen the link between microcirculatory derangements and lactic acidosis over time and would 
strengthen the conclusion that prolonged hyperlactatemia is the result of persistent microcirculatory impairment.

In conclusion, early decreases in perfused vessel density and increases in microcirculatory heterogeneity are associated with an increased intensity and duration of lactic acidosis after cardiac surgery. Further research to determine the weighted effects of specific abnormalities in capillary blood flow would be useful for guiding targeted interventions to improve tissue perfusion.

\section{ACKNOWLEDGMENTS}

The authors are extremely grateful to the subjects who took part in the presented study, support from the Abramson Emergency Medicine \& Critical Care Research Fund, the ESICM Next Fellowship which enabled the microcirculation research mentorship experience, and the University of Pennsylvania's Center for Resuscitation Science for its continued research support and guidance.

\section{REFERENCES}

1. Algarni KD, Maganti M, Yau TM: Predictors of low cardiac output syndrome after isolated coronary artery bypass surgery: trends over 20 years. Ann Thorac Surg 92(5):1678-1684, 2011.

2. Gomes WJ, Carvalho AC, Palma JH, Teles CA, Branco JN, Silas MG, Buffolo E: Vasoplegic syndrome after open heart surgery. J Cardiovasc Surg (Torino) 39(5):619-623, 1998.

3. De Backer D, Dubois M-J, Schmartz D, Koch M, Ducart A, Barvais L, Vincent JL: Microcirculatory alterations in cardiac surgery: effects of cardiopulmonary bypass and anesthesia. Ann Thorac Surg 88(5):1396-1403, 2009.

4. Ranucci M, De Toffol B, Isgrò G, Romitti F, Conti D, Vicentini M: Hyperlactatemia during cardiopulmonary bypass: determinants and impact on postoperative outcome. Crit Care Lond Engl 10(6):R167, 2006.

5. Raper RF, Cameron G, Walker D, Bowey CJ: Type B lactic acidosis following cardiopulmonary bypass. Crit Care Med 25(1):46-51, 1997.

6. Levy B, Desebbe O, Montemont C, Gibot S: Increased aerobic glycolysis through beta2 stimulation is a common mechanism involved in lactate formation during shock states. Shock 30(4):417-421, 2008.

7. Hajjar LA, Almeida JP, Fukushima JT, Rhodes A, Vincent J-L, Osawa EA, Galas FRBG: High lactate levels are predictors of major complications after cardiac surgery. J Thorac Cardiovasc Surg 146(2):455-460, 2013.

8. Lopez-Delgado JC, Esteve F, Javierre C, Torrado H, Rodriguez-Castro D, Carrio ML, Farrero E, Skaltsa K, Mañez R, Ventura JL: Evaluation of serial arterial lactate levels as a predictor of hospital and long-term mortality in patients after cardiac surgery. J Cardiothorac Vasc Anesth 29(6):1441-1453, 2015.

9. Lindsay AJ, Xu M, Sessler DI, Blackstone EH, Bashour CA: Lactate clearance time and concentration linked to morbidity and death in cardiac surgical patients. Ann Thorac Surg 95(2):486-492, 2013.

10. Stenberg TA, Kildal AB, Sanden E, How O-J, Hagve M, Ytrehus K, Larsen TS, Myrmel T: The acute phase of experimental cardiogenic shock is counteracted by microcirculatory and mitochondrial adaptations. PLoS One 9(9):e105213, 2014.

11. Bansch P, Flisberg P, Bentzer P: Changes in the sublingual microcirculation during major abdominal surgery and post-operative morbidity: microcirculation and outcome after surgery. Acta Anaesthesiol Scand 58(1):89-97, 2014.

12. Dekker NAM, Veerhoek D, Koning NJ, Leeuwen ALI, Elbers PWG, Brom CE, Vonk ABA, Boer C: Postoperative microcirculatory perfusion and endothelial glycocalyx shedding following cardiac surgery with cardiopulmonary bypass. Anaesthesia 74(5):609-618, 2019.

13. Bouattour K, Teboul J-L, Varin L, Vicaut E, Duranteau J: Preload dependence is associated with reduced sublingual microcirculation during major abdominal surgery. Anesthesiology 130(4):541-549, 2019.

14. Koning NJ, Simon LE, Asfar P, Baufreton C, Boer C: Systemic microvascular shunting through hyperdynamic capillaries after acute physiological disturbances following cardiopulmonary bypass. Am J Physiol Heart Circ Physiol 307(7):H967-H975, 2014.

15. Greenwood JC, Jang DH, Hallisey SD, Gutsche JT, Horak J, Acker MA, Bermudez CA, Zhou VL, Chatterjee S, Shofer FS, et al.: Severe impairment of microcirculatory perfused vessel density is associated to post-operative lactate and acute organ injury after cardiac surgery. $J$ Cardiothorac Vasc Anesth 35(1):106-115, 2021

16. den Uil CA, Lagrand WK, Spronk PE, van Domburg RT, Hofland J, Lüthen C, Brugts JJ, van der Ent M, Simoons ML: Impaired sublingual microvascular perfusion during surgery with cardiopulmonary bypass: a pilot study. J Thorac Cardiovasc Surg 136(1):129-134, 2008.

17. Harris PA, Taylor R, Thielke R, Payne J, Gonzalez N, Conde JG: Research electronic data capture (REDCap) — a metadata-driven methodology and workflow process for providing translational research informatics support. $J$ Biomed Inform 42(2):377-381, 2009.

18. Harris PA, Taylor R, Minor BL, Elliott V, Fernandez M, O'Neal L, McLeod L, Delacqua G, Delacqua F, Kirby J, et al.: The REDCap consortium: building an international community of software platform partners. J Biomed Inform 95:103208, 2019.

19. Shiang K-D: The SAS ${ }^{\circledR}$ Calculations of Areas Under the Curve (AUC) for Multiple Metabolic Readings. Available at: https://www.lexjansen.com/wuss/ 2004/posters/c_post_the_sas_calculations_.pdf. Accessed October 19, 2020.

20. Hutchings S, Watts S, Kirkman E: The Cytocam video microscope. A new method for visualising the microcirculation using Incident Dark Field technology. Clin Hemorheol Microcirc 62(3):261-271, 2016.

21. Bol ME, Beurskens DMH, Delnoij TSR, Roekaerts PMHJ, Reutelingsperger CPM, Delhaas T, van de Poll MCG, Sels J-WEM, Nicolaes GAF: Variability of microcirculatory measurements in critically ill patients. Shock 54(1):9-14, 2020.

22. Hessler M, Arnemann P-H, Zamit F, Seidel L, Kampmeier T-G, Kathöfer U, Morelli A, Ince C, Rehberg SW, Ertmer C: A new complimentary web-based tool for manual analysis of microcirculation videos: validation of the Capillary Mapper against the current gold standard AVA 3.2. Microcirculation 25(8):e12505, 2018.

23. Massey MJ, Larochelle E, Najarro G, Karmacharla A, Arnold R, Trzeciak S, Angus DC, Shapiro NI: The microcirculation image quality score: development and preliminary evaluation of a proposed approach to grading quality of image acquisition for bedside videomicroscopy. J Crit Care 28(6):913-917, 2013.

24. Ince C, Boerma EC, Cecconi M, De Backer D, Shapiro NI, Duranteau J, Pinsky MR, Artigas A, Teboul J-L, Reiss IKM, et al.:, Cardiovascular Dynamics Section of the ESICM. Second consensus on the assessment of sublingual microcirculation in critically ill patients: results from a task force of the European Society of Intensive Care Medicine. Intensive Care Med 44(3):281-299, 2018.

25. for the microSOAP study group, Vellinga NAR, Boerma EC, Koopmans M, Donati A, Dubin A, Shapiro NI, Pearse RM, van der Voort PHJ, Dondorp AM, Bafi T, et al.: Mildly elevated lactate levels are associated with microcirculatory flow abnormalities and increased mortality: a microSOAP post hoc analysis. Crit Care 21(1):255, 2017.

26. Hutchings SD, Naumann DN, Hopkins P, Mellis C, Riozzi P, Sartini S, Mamuza J, Harris T, Midwinter MJ, Wendon J: microcirculatory impairment is associated with multiple organ dysfunction following traumatic hemorrhagic shock: the MICROSHOCK study. Crit Care Med 46(9):e889-e896, 2018.

27. Greenwood JC, Jang DH, Spelde AE, Gutsche JT, Horak J, Acker MA, Kilbaugh TJ, Shofer FS, Augoustides JGT, Bakker J, et al. Low microcirculatory perfused vessel density and high heterogeneity are associated with increased intensity and duration of lactic acidosis after cardiac surgery with cardiopulmonary bypass. Zenodo Data Repos. Available at: https://10.5281/zenodo.4106205. Accessed October 19, 2020.

28. Hernández G, Ospina-Tascón GA, Damiani LP, Estenssoro E, Dubin A, Hurtado J, Friedman G, Castro R, Alegría L, Teboul J-L, et al.:, for the ANDROMEDASHOCK Investigators and the Latin America Intensive Care Network (LIVEN) / sb:collaboration $>$ Effect of a resuscitation strategy targeting peripheral perfusion status vs serum lactate levels on 28-day mortality among patients with septic shock: the ANDROMEDA-SHOCK randomized clinical trial. JAMA 321(7):654-664, 2019.

29. Maillet J-M, Le Besnerais P, Cantoni M, Nataf P, Ruffenach A, Lessana A, Brodaty D: Frequency, risk factors, and outcome of hyperlactatemia after cardiac surgery. Chest 123(5):1361-1366, 2003.

30. Leeuwen ALI, Dekker NAM, Jansma EP, Boer C, Brom CE: Therapeutic interventions to restore microcirculatory perfusion following experimental hemorrhagic shock and fluid resuscitation: a systematic review. Microcirculation 27:e12650, 2020.

31. den Uil CA, Caliskan K, Lagrand WK, van der Ent M, Jewbali LSD, van Kuijk JP, Spronk PE, Simoons ML: Dose-dependent benefit of nitroglycerin on microcirculation of patients with severe heart failure. Intensive Care Med 35(11):1893-1899, 2009.

32. Yeh Y-C, Wang M-J, Chao A, Ko W-J, Chan W-S, Fan S-Z, Tsai J-C, Sun W-Z: Correlation between early sublingual small vessel density and late blood lactate level in critically ill surgical patients. J Surg Res 180(2):317-321, 2013.

33. Wu Q, Gao W, Zhou J, He G, Ye J, Fang F, Luo J, Wang M, Xu H, Wang W: Correlation between acute degradation of the endothelial glycocalyx and microcirculation dysfunction during cardiopulmonary bypass in cardiac surgery. Microvasc Res 124:37-42, 2019. 
34. Dekker NAM, Veerhoek D, van Leeuwen ALI, Vonk ABA, van den Brom CE, Boer C: Microvascular alterations during cardiac surgery using a heparin or phosphorylcholine-coated circuit. J Cardiothorac Vasc Anesth 34(4):912-919, 2020.

35. Schmitz V, Schaser K-D, Olschewski P, Neuhaus P, Puhl G: In vivo visualization of early microcirculatory changes following ischemia/reperfusion injury in human kidney transplantation. Eur Surg Res 40(1):19-25, 2008.

36. Klijn E, Den Uil CA, Bakker J, Ince C: The heterogeneity of the microcirculation in critical illness. Clin Chest Med 29(4):643-654, 2008.

37. Ellis CG, Bateman RM, Sharpe MD, Sibbald WJ, Gill R: Effect of a maldistribution of microvascular blood flow on capillary $\mathrm{O}$ (2) extraction in sepsis. Am J Physiol Heart Circ Physiol 282(1):H156-H164, 2002.

38. Humer MF, Phang PT, Friesen BP, Allard MF, Goddard CM, Walley KR: Heterogeneity of gut capillary transit times and impaired gut oxygen extraction in endotoxemic pigs. J Appl Physiol 81(2):895-904, 1996.

39. Walley KR: Heterogeneity of oxygen delivery impairs oxygen extraction by peripheral tissues: theory. J Appl Physiol 81(2):885-894, 1996.

40. Piiper J: Perfusion, diffusion and their heterogeneities limiting blood-tissue $\mathrm{O} 2$ transfer in muscle: perfusion, diffusion and heterogeneities. Acta Physiol Scand 168(4):603-607, 2000.
41. Hilty MP, Guerci P, Ince Y, Toraman F, Ince C: MicroTools enables automated quantification of capillary density and red blood cell velocity in handheld vital microscopy. Commun Biol 2(1):217, 2019.

42. Hilty MP, Akin S, Boerma C, Donati A, Erdem Ö, Giaccaglia P, Guerci P, Milstein DM, Montomoli J, Toraman F, et al.: Automated algorithm analysis of sublingual microcirculation in an international multicentral database identifies alterations associated with disease and mechanism of resuscitation. Crit Care Med 48(10):e864-e875, 2020.

43. Lima A, van Rooij T, Ergin B, Sorelli M, Ince Y, Specht PAC, Mik EG, Bocchi L, Kooiman K, de Jong N, et al.: Dynamic contrast-enhanced ultrasound identifies microcirculatory alterations in sepsis-induced acute kidney injury. Crit Care Med 46(8):1284-1292, 2018.

44. Verdant CL, De Backer D, Bruhn A, Clausi CM, Su F, Wang Z, Rodriguez H, Pries AR, Vincent J-L: Evaluation of sublingual and gut mucosal microcirculation in sepsis: a quantitative analysis. Crit Care Med 37(11):2875-2881, 2009.

45. Hilty MP, Merz TM, Hefti U, Ince C, Maggiorini M, Pichler Hefti J: Recruitment of non-perfused sublingual capillaries increases microcirculatory oxygen extraction capacity throughout ascent to $7126 \mathrm{~m}$. J Physiol 597(10):2623$2638,2019$.
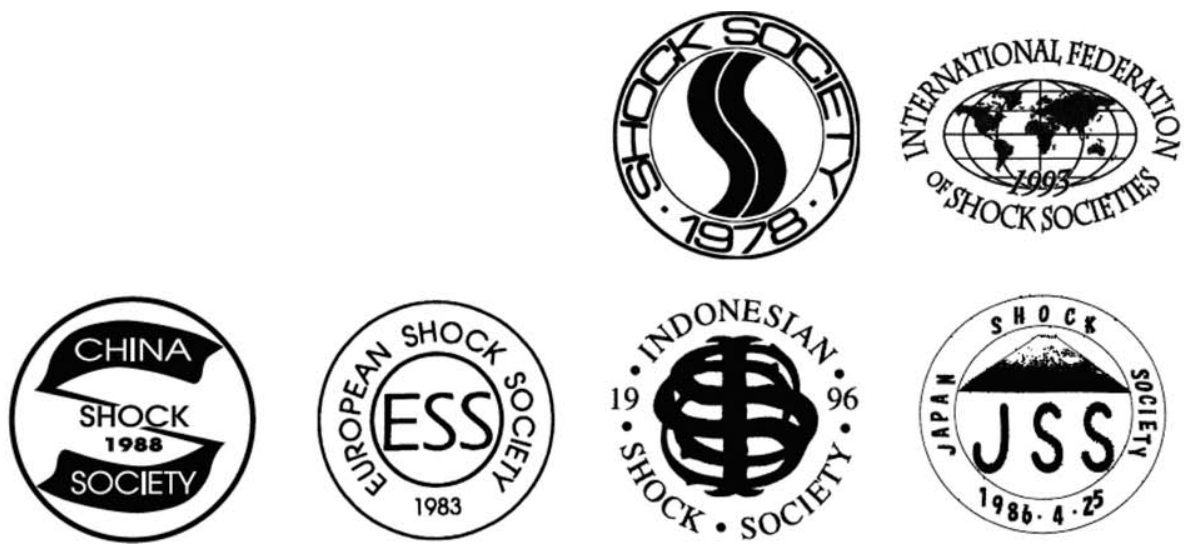

Copyright @ 2021 by the Shock Society. Unauthorized reproduction of this article is prohibited. 